\title{
Plantão psicológico como modalidade de atendimento em Psicologia Escolar: limites e possibilidades
}

\section{Psychological emergency attendance as a psychological service in educational psychology: limits and possibilities}

\author{
Edson do Nascimento Bezerra* \\ Universidade da Amazônia - UNAMA, Belém, Pará, Brasil
}

\begin{abstract}
RESUMO
As práticas de Plantão Psicológico na escola dissociam tais intervenções das atividades da Psicologia Escolar, assim como relacionam essa modalidade à necessidade da implementação de um serviço que lhe dê a devida visibilidade institucional. Este trabalho considera tais referências passíveis de reflexão a partir da prática profissional do autor e da leitura atualizada em Psicologia Escolar. Para este fim, toma-se como referência o conceito de Clínica Ampliada e sua correlação com a modalidade de atendimento Plantão Psicológico. Problematiza-se a oportunidade do psicólogo ou psicóloga escolar, dentre outras ações, possibilitar escuta e acolhimento a qualquer pessoa da comunidade escolar que busque esse apoio de modo espontâneo no momento de sua emergência. Para isso, reflete-se sobre a condição do Plantão Psicológico como serviço e como modalidade de atendimento na escola, bem como sobre a psicologia escolar como área de atuação inserida nesse meio complexo de olhares e perspectivas.
\end{abstract}

Palavras-Chaves: plantão, clínica ampliada, psicologia, escola.

\begin{abstract}
The School Psychology Emergency Practices differs from others School Psychology practices, is more than type of psychology service and should have more institutional visibility. This paper reflects on these references from both the practice of the author and the currently literature in school psychology. To this purpose, we use as reference the concept of Extended Clinic and its relation with Psychology Emergency Service area. We discuss the opportunity of the school psychologist has, among other things, to be able to listen and to welcome spontaneously anyone in the school community seeking for support in case of emergency. In so doing, the author reflects on the condition of psychological emergency service as service and as a type of treatment at school, and school psychology as an area of expertise inserted in this complex environment different of views and perspectives.
\end{abstract}

Keywords: emergency, extended clinic, psychology, school. 


\section{I ntrodução}

O convite à possível (e necessária) articulação entre Psicologia Clínica (área de aplicação da Clínica em Psicologia) e Práticas Sociais, ampliando horizontes da primeira e mobilizando novas possibilidades de ação da segunda, de acordo com a temática central do IV Congresso Latino Americano de Psicoterapia Existencial e Enfoques Afins, oportuniza-nos desenvolver, neste artigo, o desafio de uma prática clínica em Plantão Psicológico ${ }^{1}$, modalidade de atendimento originariamente identificada com a Abordagem Centrada na Pessoa (ACP) e genuinamente brasileira ${ }^{2}$, como um meio possível de atuação em Psicologia Escolar.

A prática profissional deste autor serviu como elemento mobilizador para as questões disparadoras deste artigo. As práticas em Psicologia Escolar podem ser potencializadas por modalidades de intervenção provenientes da Clínica? Tal questão decorre do discurso comum, principalmente no período da Formação em Psicologia, para que não se faça clínica na escola. Derivada dessa questão, o que podemos entender por Clínica e, por conseguinte, Psicologia Clínica, e de que modo ela pode subsidiar outras áreas de atuação em Psicologia? Continuando e especificando para o Plantão Psicológico, pergunta-se se este é uma modalidade de atendimento clínico, um serviço ou ambas as coisas. Caso seja esta última alternativa, a modalidade depende absolutamente da implantação do serviço? Por conseguinte, o Plantão Psicológico, como modalidade, pode vir a ser uma prática possível à atuação em Psicologia Escolar?

Não pretendemos obter respostas definitivas sobre tais questões. Propomos estabelecer parâmetros de reflexão, sustentados teoricamente, porém sem desconsiderar a nossa experiência profissional na área, acerca dos desafios verificados na tentativa de adequar uma estratégia de atendimento clínico, como o Plantão Psicológico, às atribuições específicas da Psicologia Escolar.

\section{O lugar da clínica em Psicologia}

Inicialmente, precisamos definir de modo claro o que entendemos por Clínica e suas possíveis intercalações com o fazer psicológico. Não se trata de uma prática restrita à Psicologia. É própria de qualquer área profissional voltada ao estabelecimento de relações de cuidado com o outro, sujeito ou grupo social, que expresse sofrimento e demande este cuidado.

O que vai caracterizar a clínica, no meu entender, é, antes de mais nada, a submissão do sujeito a um outro que irrompe e se eleva à sua frente, expressando sofrimento, fazendo-lhe exigências, desafiando sua capacidade de atenção e hospedagem, escapando em 
maior ou menor intensidade ao campo de seus conhecimentos e representações, furtando-se ao seu domínio, desalojando-o. Mas, será também este mesmo outro que na sua penúria e no seu maior desamparo pode assumir diante do sujeito uma posição ensinante. Clínica é, assim, inclinar-se diante de, dispor-se a aprender-com, mesmo que a meta, a médio prazo, seja aprender-sobre. (Figueiredo, 2009, p.166, grifos do autor)

Assim, além de uma relação de ajuda profissional que estabelece papéis específicos nessa relação, ou seja, o lugar do cuidador e o lugar do outro, que demanda cuidado, a Clínica estabelece um modo de ensino peculiar, em que o cuidador aprenderá com esse outro o modo próprio, singular, que permita que o outro, com toda sua alteridade, mostre-se e seja nessa relação, possibilitando o trabalho do cuidador sobre o sofrimento expressado (Figueiredo, 2009). A Clínica, deste modo, é um método, e o clinicar, propriamente dito, a expressão de uma metodologia específica a ser construída em favor de uma relação de cuidado para com o outro. “(...) Dessa forma, o cuidar deve localizar-se como processo interativo, que só ocorre em relação ao outro, razão pela qual o modo de ser do cuidado envolveria relação não de sujeito-objeto, mas sim de sujeito-sujeito". (Oliveira, 2009, p.117)

Essa relação de cuidado, mais do que procedimentos e técnicas a serem estabelecidas a posteriori, pressupõe determinados comportamentos que privilegiem o modo de estar com o outro, como respeito, consideração, atenção, solidariedade, gentileza e interesse, por exemplo. Verificamos uma enorme proximidade com Amatuzzi (2010), em que a Abordagem Centrada na Pessoa (ACP), mais do que uma abordagem psicoterápica, com procedimentos estabelecidos de modo generalista, representa, nesta perspectiva, uma prática clínica, não exclusiva de um fazer psicológico, que prioriza um modo de ser fundamentado em atitudes:

A Abordagem Centrada na Pessoa (ACP) encontra-se nas atitudes e valores subjacentes ao agir. Ela pode levar consistentemente a formas de agir conforme as situações, as pessoas, os momentos. A consistência última da ACP não está no nível de sua utilidade ou mesmo de sua eficácia, mas no nível do seu valor. Se não tenho sensibilidade para valores, jamais entenderei a abordagem centrada na pessoa; a não ser que a entenda como mera técnica. Mas, em última instância, ela não se justifica como uma técnica e sim, como uma ética: uma ética das relações humanas (interpessoais, comunitárias, sociais, políticas). Justificar a ACP é explicitar e fundamentar, no plano teórico, os valores que ela expressa. (p.23) 
As diferentes formas de agir derivadas da atitude clínica em Psicologia são reconhecidas como psicoterapias. É comum confundirmos ou tratarmos de modo semelhante Psicologia Clínica e Psicoterapia, definição formatada como um modo de atendimento psicológico diádico, exercido em âmbito privado, privilegiando fundamentalmente o individual e o intrapessoal, de caráter universalista, a-social e a-histórico.

Se compreendermos as psicoterapias como diferentes tipos de tecnologia de cuidado criados a partir de determinadas condições e demandas sócio-histórico-culturais, fundamentados em construtos teóricos específicos, como modos de fazer que oferecem recursos instrumentais favoráveis ao estabelecimento e manejo de vínculos propícios às relações de ajuda, poderemos nos perguntar, tal qual Marcus Vinícius de Oliveira, em fala feita na mesa A ação clínica e os espaços institucionais das políticas públicas: desafios éticos e técnicos ${ }^{3}$, em 2009:

Por que será que nós, na Psicologia, temos esse costume paroquial, tão próprio da nossa comunidade, de chamar as tecnologias psicoterapêuticas em suas várias correntes, de clínica? De nos referir às psicoterapias como sendo sinônimo de clínica em Psicologia? Por que essa associação: faço clínica quando sou psicoterapeuta ou sou psicólogo clínico porque sou psicoterapeuta? Por que na Psicologia vigora essa grosseira redução da clínica, como método, em mera expressão particular do exercício de uma das tecnologias psicoterapêuticas metodologicamente estabelecidas? (Oliveira, 2009, p.112-113)

Para além desse olhar reducionista, podemos considerar a multiplicidade de dimensões envolvidas nas demandas apresentadas em Clínica, o que exige a necessária articulação com saberes e práticas afins para atender à complexidade de tais demandas. Além disso, com a ampliação da noção de cidadania no país, a partir da Constituição de 1988, incluindo novos contingentes sociais na condição de sujeitos com acesso ao atendimento clínico em diferentes espaços institucionais como hospitais, presídios, escolas, postos de saúde, centros comunitários (Oliveira, 2009), sempre para além do setting clínico clássico, ou seja, o consultório particular, a Psicologia Clínica precisou ampliar seu modo de atuação para atender essa nova demanda emergente.

Assim, "(...) o método clínico é uma atitude, .... uma forma de raciocinar, um modo de operação que pode ser aplicado à organização, à escola, pode ser aplicado, inclusive, à comunidade." (Oliveira, 2009, p.124). A ampliação da Clínica não representa uma negação da validade específica dos modelos psicoterápicos, apenas 
uma nova adequação do método clínico a diferentes contextos de ação. Em Psicologia, enquanto uma modalidade de atendimento clínico que priorize o cuidado a partir do estar-com e ser-com (Oliveira, 2009), fundamentada na ACP enquanto modo de ser valorativo que referencie todo modo de fazer derivado (Amatuzzi, 2010), podemos falar do Plantão Psicológico, independente da sua condição de Serviço?

\section{Plantão psicológico enquanto modalidade de serviço}

A compreensão corrente acerca do Plantão Psicológico pressupõe um Serviço exercido por profissionais de Psicologia ou estudantes sob supervisão de um profissional dessa área que se disponibilizam a atender, em local, dias e horários pré-estabelecidos, pessoas que fazem parte de um determinado grupo social identificado com um espaço institucional e/ou comunitário que podem procurar espontaneamente esse Serviço a partir de uma demanda emergente ou quase emergente vivenciada.

$\mathrm{O}$ atendimento em Plantão

“(...) objetiva facilitar uma maior compreensão da pessoa e da sua situação imediata. O plantonista e o cliente vão juntos procurar no 'momento-já' as potencialidades inerentes que podem estar adormecidas ou que precisem ser deflagradas a partir de uma relação calorosa, sem julgamentos, onde a escuta sensível e empática, a expressividade do plantonista e seu genuíno interesse em ajudar, desempenham papel primordial" (Tassinari, 1999, p.55).

A plasticidade do Plantão pressupõe pensarmos em sua adequação a diferentes contextos sócio-culturais em que o profissional da Psicologia é solicitado a atuar de modo direto. Esse fator serve de justificativa, inclusive, para o surgimento de experiências de Plantão Psicológico fundamentada em outras perspectivas teóricometodológicas diferentes da ACP, como Gestalt-Terapia, CognitivaComportamental ou Psicodinâmica, por exemplo. Verificamos, nesse caso, uma valorização do Plantão enquanto Serviço passível de ser disponibilizado como estratégia viável de acesso à escuta e ao cuidado clínico em Psicologia em distintos contextos sociais.

Sem diminuir a importância dessa abertura de possibilidades, pretendemos focar sobre o modo como esses atendimentos em Plantão Psicológico são oferecidos. Mais do que pontuar essa prática sobre vagos conceitos, como o da oferta de uma escuta psicológica (passível de diferentes compreensões, conforme a perspectiva teórica que Ihe sirva de base), por exemplo, queremos refletir sobre a 
possibilidade do Plantão Psicológico como uma modalidade de atendimento clínico à luz da ACP.

Segundo Rocha (2009), "o plantão é uma modalidade de atendimento psicológico que se propõe a acolher as pessoas que o procuram no momento de sua angústia, auxiliando-a no esclarecimento de sua demanda". (p.109). Assim, enquanto modalidade, que aspectos vivenciados pelo(a) plantonista pode caracterizar e, por conseguinte, identificar o Plantão Psicológico enquanto tal, diferenciado-o, inclusive, de um modo de Psicoterapia Breve?

Primeiramente, elencamos a necessária disponibilidade incondicional para o atendimento por parte do(a) plantonista. Entendemos que esse momento inicial do Plantão pressupõe a atitude de abertura ao desconhecido que advirá com a procura de alguém por atendimento. Não é um procedimento técnico, pois não impõe comportamentos preestabelecidos por parte do (a) plantonista. Como atitude, aproxima-se diretamente da consideração positiva e incondicional verificada por Rogers (2008) como aspecto facilitador de uma relação verdadeiramente terapêutica.

(...) a abertura que caracteriza o plantão, a abertura que apóia e provoca a descoberta do impensado, que acolhe e respeita a diversidade, que evidencia a instabilidade, que angustia e permite a criação do novo, é essa abertura que mantém em nós a prática do trabalho com Plantão Psicológico (Rocha, 2009, p.109).

Em seguida, diante da exposição inicial por parte de quem procura o atendimento, essa modalidade propõe que o(a) plantonista ofereça uma escuta esclarecedora e facilitadora da demanda apresentada. Não se trata, nesse caso, apenas de entender o sentido lógico do problema apresentado para, junto com a pessoa que procurou 0 atendimento, buscar necessariamente soluções adequadas. Escuta esclarecedora, nesse caso, refere-se à compreensão do modo como a demanda é percebida pela pessoa atendida. O termo esclarecimento significa esta perspectiva fenomenológica de devolução ao outro do sentido que a sua demanda possui para si. É um processo de construção intersubjetiva e processual, em que esse sentido não é estabelecido pelo(a) plantonista e, muito menos, confundido como uma verdade anunciada.

Essa escuta também é facilitadora, pois possibilita, concomitantemente, o consequente acesso às possibilidades que se abrem a partir do momento em que essa pessoa se apropria do sentido que sua demanda possui para si. De modo análogo, essa escuta esclarecedora e facilitadora corresponde à atitude de 
compreensão empática considerada como favorecedora da efetividade da relação psicoterápica.

O caminho percorrido “(...) durante o atendimento de plantão é o da escuta, da compreensão e da comunicação, dentro de uma perspectiva fenomenológica, não é tomar conhecimento do compreendido, mas o desenvolvimento das possibilidades e seus desdobramentos constituem interpretações. A compreensão é uma busca incessante, porém inalcançável, pois jamais poderemos entrar em contato com todas as possibilidades; elas são sempre projeções, no sentido de vir-aser." (p.107)

Por fim, podemos identificar um momento de desdobramentos do processo de encontro. A clareza da delimitação do encontro para os seus participantes favorece uma maior implicação dos mesmos na exploração mútua das possibilidades surgidas no decorrer deste processo. Não cabe falarmos em encaminhamentos ou acordos preestabelecidos referentes à continuidade do atendimento. A força do Plantão Psicológico, segundo todas as pesquisas realizadas (Mahfoud, 1999; Tassinari, 1999), encontra-se justamente na potencialização derivada desse encontro único e singular, a partir de uma demanda espontânea e emergente, ou quase emergente. Dessa forma, preestabelecer uma quantidade específica de encontros ou condicionar a efetividade desse encontro a necessários encaminhamentos é podermos confundir procedimentalmente o Plantão Psicológico com um modo de Psicoterapia Breve, por exemplo. Isso não exclui a possibilidade de nova procura de atendimento por parte da pessoa. O alerta é que este movimento possa ser absolutamente espontâneo e delimitado pelos(as) plantonistas para que não prive essa pessoa de buscar um acompanhamento psicoterápico, caso seja necessário. O aspecto mais significativo desse momento é a possibilidade de ressignificação perceptiva por parte da pessoa que buscou o Plantão. Se essa mudança de percepção da demanda trazida derivará um encaminhamento, essa questão é, de fato, secundária no processo de atendimento do Plantão.

Uma das características do Plantão Psicológico é ajudar a pessoa a clarear seu pedido de ajuda, ao reorganizar sua vivência, para que ela (só então) possa decidir se vai retornar ou não e identificar melhor se precisa de encaminhamento para outro serviço ou tratamento. Este olhar do plantonista permite que a pessoa utilize seu poder pessoal. (Tassinari, 1999, p.123). 
É indiscutível a importância da oferta de Serviços de Plantão Psicológico em contextos institucionais das mais diferentes naturezas. De acordo com Miguel Mahfoud, em reunião recente (outubro/2011) junto ao Grupo de Pesquisa de Plantão Psicológico da Universidade Federal do Pará, trata-se de "criar uma estrutura dentro de outra estrutura que privilegie os processos pessoais". Porém, se entendermos, conforme Rocha (2009), que o Plantão possui um sentido que vai além dessa organização estrutural, que se relaciona a uma modalidade que parte da abertura e da disposição para receber quem procura esse atendimento (disponibilidade incondicional para o atendimento), ouve e acompanha o relato dessa demanda apresentada para, de forma dialogada, compreender o seu sentido existencial para a pessoa que a traz (escuta esclarecedora e facilitadora), favorecendo a emersão de um projeto de cuidado coerente e significativo a essa pessoa que buscou o Plantão (desdobramentos do processo de encontro), poderemos refletir então sobre possibilidades criativas e dinâmicas dessa modalidade associadas a diferentes contextos e práticas profissionais em Psicologia. Considerando isso, parece-nos interessante e necessário compreender esta possibilidade em Psicologia Escolar e de que modo isso pode ocorrer sem o risco de um retrocesso à existência de práticas clínicas que transformem a escola em uma extensão do setting terapêutico.

\section{Psicologia Escolar e atendimento individual}

As práticas em Psicologia no contexto escolar brasileiro caracterizaram-se, até aproximadamente o final da década de 70 do século passado, por adotar um modelo clínico tradicional individualista, descontextualizado, adaptacionista, acrítico e, por conseguinte, excludente. Essa perspectiva de atuação tornou-se obsoleta e ultrapassada para a concepção educacional, de natureza crítica e contextualizada socialmente, que passou a vigorar no Brasil a partir da última década do século XX, principalmente após a promulgação da Lei de Diretrizes e Bases da Educação Brasileira (LDB) em 1996. Assim, a escola passou a ser considerada

(...) um espaço contraditório, dinâmico, confuso, divergente, atravessado por muitas outras 'instituições', tais como: a organização política ou não dos moradores do bairro e dos professores; a participação maior ou menor dos pais e o conhecimento de seus direitos a respeito da escola, do significado do espaço escolar no bairro e sua utilização pelos moradores; nos motivos pelos quais um ou outro professor havia escolhido (ou não) estar trabalhando nessa escola; no 
entrelaçamento de histórias individuais desses professores e das crianças, etc. Essas observações apontavam para o fato de que cada escola se constitui em um espaço historicamente construído por aqueles que o compõem, e na impossibilidade de encontrarmos duas escolas iguais, pois as redes de relações e as práticas nelas existentes são singulares. (Machado e Souza, 2004, p.49)

Neste enfoque, a Psicologia Escolar necessita estar inserida no cotidiano escolar para melhor compreender e intervir nos processos que constituem as relações na escola, formadas por diferentes protagonistas como alunos, professores, corpo técnico, direção, dentre outros, inseridos em uma dinâmica histórico-cultural própria, cujas escolhas e práticas serão decisivas para o sucesso ou fracasso escolar (Souza, 2004).

Observa-se, no entanto, um desconhecimento generalizado no meio escolar sobre o papel específico da Psicologia nesse contexto. Há o risco da ausência de exigências críticas quanto ao trabalho desenvolvido por esse profissional, por pura falta de esclarecimento, ou mesmo a expectativa de uma atuação relacionada exclusivamente ao psicodiagnóstico clínico, por exemplo, que desconsidera a diversidade dos possíveis fatores escolares constituintes de uma demanda apresentada (Guzzo, 2008; Correia e Campos, 2004; Machado e Souza, 2004). Para romper com esse desconhecimento e preconceito histórico referente ao psicólogo, muitas vezes equivocadamente identificado como o profissional que trata dos "alunos-problema" da escola, precisamos reconhecer os limites da Psicologia para lidar isoladamente com as demandas escolares.

"A abertura da Psicologia para atuar em interface com outras áreas tem sido uma recomendação constante nos contextos institucionais. No que se refere à Psicologia Escolar, os sinais de que a área está ultrapassando esse isolamento demonstram - amadurecimento da atuação nessa área da Psicologia." (Neves, 2009, p.71)

Apesar de muitos teóricos entenderem ser absolutamente um retrocesso a possibilidade de atendimento individual em Psicologia Escolar, queremos chamar a atenção para a peculiaridade e diferença do horizonte histórico-cultural em que está inserida a escola em nossos dias se comparada a décadas atrás. Não a tratamos (escola) mais como uma instituição inquestionável em seu modo de proceder e inviolável enquanto mantenedora dos valores socialmente respeitáveis. Trata-se de uma complexa rede de relações multifacetadas, heterogênea em seus discursos e práticas (Souza, 2004), cuja compreensão amplia e instrumentaliza o profissional da 
Psicologia a melhor lidar (em uma espécie de escuta esclarecedora e facilitadora) com as queixas escolares que podem ocorrer inclusive (e não absolutamente) por demanda individual, espontânea e emergente ou quase emergente, requerendo do profissional da Psicologia a disponibilidade incondicional para o atendimento, própria do Plantão Psicológico.

Dentre diversos outros modos de atuação, como análise institucional, identificação dos comportamentos influenciados pelo sistema escolar, compreensão dos modos de relação existentes dentro da escola, conhecimento das necessidades e defesa dos direitos das crianças e adolescentes inseridos no contexto escolar, apoio técnico e metodológico aos profissionais docentes e não docentes da escola (Correia e Campos, 2004; Guzzo, 2008), precisamos considerar a legitimidade do atendimento individual que ocorre espontaneamente no contexto escolar. Segundo Correia e Campos (2004),

Não seria aconselhável subestimar a influência do individual no contexto escolar e, tampouco, a influência deste nas dificuldades individuais. Nesse sentido, há de se considerar as queixas relacionadas ao aluno ou à aluna (bem como a qualquer outro membro dessa comunidade escolar), embora analisando-as sob várias óticas (p.170).

Ou seja, não basta atender de modo descontextualizado e acrítico. 0 convite é considerar que outros possíveis fatores, no contexto escolar, podem ter algum tipo de contribuição à queixa apresentada. Assim, os desdobramentos do processo de encontro, no caso específico de um possível atendimento na modalidade de Plantão Psicológico em Psicologia Escolar, envolvem, mais do que a possibilidade de ressignificação perceptiva por parte da pessoa que buscou o Plantão, a mediação do Psicólogo Escolar quanto aos diferentes fatores envolvidos nessa queixa. A plasticidade dos encaminhamentos realizados, se necessários forem, precisam considerar a complexa diversidade da cultura escolar envolvida, sem abdicar, de modo absoluto, da escuta ativa e interessada do psicólogo quanto à pessoa atendida e o seu modo de percepção sobre a queixa apresentada.

A prática profissional deste autor, atuando no contexto escolar há quase quatro anos, tem mostrado que existe demanda para uma escuta clínica dentro da escola, porém não com propósitos psicoterápicos, e sim como um espaço de atenção psicológica a questões emergentes e espontâneas surgidas nesse contexto. Nos diversos momentos de procura do Serviço de Psicologia Escolar, era recorrente a demanda ser por uma escuta clínica pontual, sem que necessariamente houvesse desdobramentos em direção a um acompanhamento psicoterápico. Caso esse desdobramento ocorresse, 
evidentemente não se daria no espaço escolar. Muitas pessoas da escola - estudantes, professores e outros funcionários - procuravam - Serviço para tratar sobre questões específicas como relações interpessoais, dificuldades no estudo, problemas externos que interferiam em suas atividades dentro da escola, etc.. Quando essa procura ocorria, o modo de condução desse atendimento configuravase Plantão Psicológico como modalidade, mesmo não existindo um Serviço específico com esse nome.

\section{Considerações finais}

Para finalizar essa reflexão, precisamos elencar alguns argumentos contrários à prática do Plantão Psicológico em Psicologia Escolar como aspectos significativos para oferecer, se isso for possível, a necessária consistência ao propormos o Plantão Psicológico como modalidade de atendimento.

Um primeiro argumento mobilizado quanto ao Serviço de Plantão na escola refere-se à relação entre os plantonistas e a própria escola:

(...) O fato da equipe de plantonistas não pertencer ao quadro de funcionários da Escola, por ser um Serviço terceirizado, permite maior liberdade de temas mais pessoais e/ou críticos a serem abordados, sem constrangimento. (Tassinari, 1999, p.71).

A partir da realidade vivenciada no sistema escolar, a condição do Plantão enquanto um Serviço terceirizado não pode ser considerado regra, mas sim exceção. A não ser que venha a fazer parte de uma política pública em educação ou saúde, a maior parte das escolas, públicas e privadas, não possui qualquer convênio com Instituição de Ensino Superior que poderia ser, potencialmente, um núcleo de fomento do Serviço de Plantão Psicológico em escolas.

Além disso, conforme já foi citado, há a importância da compreensão do contexto institucional e, por conseguinte, da facilidade no estabelecimento de uma relação de confiança com um profissional que procure deixar claro, enquanto psicólogo escolar, que atua para uma comunidade escolar, e não para um grupo gestor. Ainda que essa situação seja mais desafiadora se relacionada à escola privada, é uma questão de ética e compromisso profissional do psicólogo esclarecer às pessoas da comunidade em que está inserido quanto a isso, em especial os gestores da instituição. Por outro lado, a probabilidade de intervenção da gestão é maior sobre um Serviço de Plantão Psicológico constituído formalmente na escola do que sobre o Plantão Psicológico enquanto modalidade de atendimento do(a) 
Psicólogo(a) Escolar, uma vez que, nesse caso, se trata de procedimento profissional de atuação.

Outro argumento que inviabilizaria o Plantão entre psicólogos escolares é a inadequação de uma prática relacionada à escuta das pessoas tal como se sentem e expressam suas vidas (Tassinari, 1999). Relembramos a concepção ampliada de Clínica enquanto um modo de cuidado que se adequa a diferentes contextos e rompe estereótipos absolutos e preestabelecidos, independentes da cultura institucional, sobre o que cabe ou não ao profissional da Psicologia na escola. Pensar em uma perspectiva ampliada de Clínica nesse momento histórico não significa retroceder ao reducionismo da exclusividade da prática clínica na escola, completamente inadequado pelo seu caráter alienante e descontextualizado culturalmente.

Esse caráter de cuidado proveniente do fazer clínico ampliado, que priorize o modo de estar com o outro em atitudes como respeito, compreensão, consideração e interesse, por exemplo, contribui de modo concreto para o estabelecimento de experiências educativas enquanto formadoras de pessoas em sua integralidade, muito além do restritamente intelectual.

A Educação tem pedido técnicas à Psicologia. Mas o risco é o de não se clarear a finalidade geral da educação, respondendo segundo objetivos precisos, mas inadequadas a essa finalidade. Ou seja, o risco é o de não explicitarmos (nem a nós mesmos) que a finalidade da educação é a formação da pessoa, e que queremos responder a tantas demandas com diversos objetivos definidos (aumento do rendimento escolar, auxílio na expressão verbal e escrita, aplacamento de comportamentos anti-sociais (...), podem nos ocupar muito; podemos até obter resultados, mas poderíamos ainda assim não estar respondendo à verdadeira finalidade da educação. Se a explicitarmos, nós nos daremos a oportunidade de que ela ilumine objetivos, métodos e técnicas. $E$, ainda mais importante, daremos a nós mesmos a oportunidade de sermos educadores, isto é, testemunhas de uma consciência ampla possível, que já começa a ser uma rota de orientação dentro da desorientação cultural em que vivemos, e que nossas crianças e adolescentes não têm como evitar. (Mahfoud, 1999, p.143)

Propomos repensar de modo criativo e dinâmico possibilidades de atuação da Psicologia na escola considerando seu contexto específico, como um convite a repensar novas estruturas dentro da estrutura escolar. Tais estruturas podem ser compreendidas como o Serviço ou, na sua impossibilidade, seja pelo número escasso de profissionais, seja pela ausência de um convênio que o viabilize, como práticas fundamentadas de atendimento em Psicologia Escolar. O fato é que 
uma estrutura não inviabiliza a outra. Pelo contrário, inclusive, entendemos que o Serviço necessita da clareza do modo de atendimento por parte dos plantonistas que constituam esse Serviço. Verificamos essa possibilidade a partir da nossa experiência profissional e de outros colegas da área escolar, em que somos procurados, sem qualquer encaminhamento prévio, para atendimento individual em condições inesperadas e significativamente necessárias às pessoas que o fazem. Pensar o Plantão enquanto modalidade é estabelecer um modus operandi para que possamos lidar com essa demanda de forma a mais consistente possível, ainda que o ineditismo da relação e seu caráter de imediaticidade sempre estabeleçam situações singulares de apoio e funcionamento.

Assim, podemos compreender o Plantão Psicológico como uma modalidade de atendimento fundada em bases claras disponibilidade incondicional para o atendimento, escuta esclarecedora e facilitadora e desdobramentos do processo de encontro -, sob o referencial teórico da ACP, para lidar com essa procura espontânea que ocorre no cotidiano profissional dos psicólogos escolares, cujo público não se restrinja aos alunos, mas envolva qualquer sujeito dessa comunidade que busque 0 atendimento em sua imediaticidade existencial e sem perder a prioridade original do Plantão, ou seja, o estabelecimento de espaços vivenciais de escuta (mesmo não sendo através do Serviço formalmente constituído), voltados efetivamente aos processos pessoais demandados em sua natureza imediata e emergencial.

\section{Referências}

Amatuzzi, M. M. (2010). Rogers: ética humanista e psicoterapia. Campinas: Alínea.

Correia, M. \& Campos, H. R. (2004). Psicologia escolar: histórias, tendências e possibilidades. In O. H. Yamamoto \& A. C. Neto (Orgs.). O psicólogo e a escola: uma introdução ao estudo da psicologia escolar. (pp.137-185). Natal: EDUFRN.

Figueiredo, L. C.M. (2009). Revisitando as psicologias: da epistemologia à ética das práticas e discursos psicológicos. Petrópolis:

Vozes.

Guzzo, R. S.L. (2008). Formando psicólogos escolares no Brasil, dificuldades e perspectivas. In: Wechsler, S. M. (org.) Psicologia escolar: pesquisa, formação e prática. (pp.75-92). Campinas: Alínea. Machado, A. M. \& Souza, M. P. R. (2004). As crianças excluídas da escola: um alerta para a psicologia. In: A.M.Machado \& M.P.R.de Souza (Orgs.). Psicologia escolar: em busca de novos rumos. (pp. 3954). São Paulo: Casa do Psicólogo. 
Mahfoud, M. (org.). (1999). Plantão psicológico: novos horizontes. São Paulo: Companhia ilimitada.

Neves, M. M. B. J. (2009). A atuação dos psicólogos escolares no Distrito Federal. In C. M. Marinho-Araújo (Org.) (pp.55-73). Psicologia escolar: novos cenários e contextos de pesquisa, formação e prática. Campinas: Alínea.

Oliveira, M. V. (2009). A ação clínica e os espaços institucionais das políticas públicas: desafios éticos e técnicos. Ano da Psicoterapia: textos geradores. (pp. 106-130). Brasília: Conselho Federal de Psicologia.

Rocha, M. C. (2009). Plantão psicológico: desafios e potencialidades. In J. O.Breschigliari \& M. C. Rocha (Orgs.). Serviço de aconselhamento psicológico: 40 anos de história. (pp. 103-115). São Paulo: IPUSP.

Rogers, C.R. (2008). As condições necessárias e suficientes para a mudança terapêutica da personalidade. In: J.K.Wood (Org.). Abordagem centrada na pessoa. (pp.143-162). Vitória: EDUFES.

Souza, B.P. (2004). Professora desesperada procura psicóloga para classe indisciplinada. In A. M. Machado \& M. P. R. Souza (Orgs.) Psicologia escolar: em busca de novos rumos 00.107-116. São Paulo: Casa do Psicólogo.

Tassinari, M. A. (1999). Plantão psicológico centrado na pessoa como promoção de saúde no contexto escolar. Dissertação de mestrado, Universidade Federal do Rio de Janeiro, Rio de Janeiro, RJ, Brasil.

\section{Endereço para correspondência \\ Edson do Nascimento Bezerra}

Av. Alcindo Cacela, 287, bloco F, Umarizal, CEP 66060-902, Belém - PA, Brasil.

Endereço eletrônico: en.bezerra@gmail.com

Recebido em: 22/11/2011

Reformulado em: 15/10/2013

Aceito para publicação em: 07/11/2013

Acompanhamento do processo editorial: Deise Maria Leal Fernandes Mendes

\section{Notas}

Docente Adjunto IV do Curso de Psicologia da Universidade da Amazônia (UNAMA), Psicólogo Escolar da Escola de Ensino Fundamental e Médio Tenente Rêgo Barros, Belém (PA), Brasil. Graduado em Psicologia (Universidade Federal do Pará) e Filosofia (Universidade Federal do Pará), Especialista em Psicopedagogia (Faculdade I piranga).

1 “...tipo de atendimento psicológico, que se completa em si mesmo, realizado em uma ou mais consultas sem duração predeterminada, objetivando receber qualquer pessoa no momento exato de sua necessidade para ajudá-la a compreender melhor sua emergência e, se necessário, encaminhá-la a outros serviços" (TASSINARI, 1999).

2 Surgida em 1969, no Serviço de Aconselhamento Psicológico (SAP) da Universidade de São Paulo, USP (Tassinari, 1999). 
3 Mesa-redonda realizada no V Seminário Nacional Psicologia e Políticas Públicas: Subjetividade, Cidadania e Políticas Públicas, no dia 06 de março de 2009, durante o $6^{\circ}$ Congresso Norte-Nordeste de Psicologia (CONPSI). 